\title{
DETERMINASI LOYALITAS PEREMPUAN MILENIAL TERHADAP PEMBELIAN KOSMETIK HALAL
}

\author{
Jihan Nabila Zahara ${ }^{1}$ \\ Universitas Airlangga, Indonesia \\ jihan.nabila.zahara-2019@feb.unair.ac.id
}

\begin{abstract}
This study aims to analyze the determination of millennial women's loyalty to the purchase of halal cosmetics. This study uses a quantitative survey approach by distributing questionnaires in the form of google form. The sampling technique used nonprobability purposive sampling to collect data from a sample of 223 respondents with the criteria of millennial women born in the 1980s to 2000s, Indonesian citizens and had purchased halal cosmetics in the last 6 months. The analysis technique used in this research is Structural Equation Modeling-Partial Least Square (SEM-PLS). Based on the results of the study, it shows that of the 5 hypotheses tested, all of them are accepted, namely religiosity has a significant effect on millennial women's loyalty in purchasing halal cosmetics (H1). Then, brand image (H2), profit value (H3) and halal certification (H4) have a significant and positive effect on consumer satisfaction. The high level of satisfaction also has a positive effect on the loyalty of millennial women in buying back halal cosmetic products and recommending them to others (H5). This discovery has significant implications that can help producers and distributors develop business strategies, especially halal cosmetic products.
\end{abstract}

Keywords: Loyalty, Millennial Generation, Halal Cosmetics

\section{PENDAHULUAN}

Milenial adalah kelompok generasi terbesar sejak baby boomer(Smith, 2012). Ukuran dan daya beli mereka yang besar membuat mereka menjadi target yang menarik bagi banyak industri konsumen. Diperkirakan setengah dari semua pengeluaran adalah hasil dari pembelian yang dilakukan oleh Millennials (Marketing Breakthroughs Inc, 2008). Beberapa peneliti telah menemukan bahwa generasi ini memiliki kecenderungan tinggi untuk menjadi pakar pasar. Pakar pasar adalah konsumen dengan pengetahuan produk umum yang bertindak sebagai penyebar informasi produk (Gerzema \&
D’Antonio, 2011).Wanita milenial pada umumnya sering menggunakan kosmetik dalam kesehariannya. Ini akan menciptakan peluang besar untuk menjadikan generasi milenial sebagai target pasar produk kosmetik halal ( Handriana, et al., 2020).

Produk kosmetik halal dianggap sebagai inovasi dan revolusi dalam industri kosmetik karena menawarkan produk berkualitas tinggi yang mengikuti kepatuhan halal(Khan, Sarwar, \& Tan, 2020)antara lain bahan tidak mengandung alkohol dan tidak berasal dari hewan yang termasuk haram. Selain itu, harus mengikuti penyelidikan ilmiah yang ketat untuk 
menghasilkan produk yang murni, aman, dan menggunakan bahan alami terbaik(Khan, Sarwar, \& Tan, 2020).Bagi umat Islam, produk bersertifikat halal dengan logo halal membawa ketenangan pikiran karena menjadi penanda utama pembeda produk halal dan non halal. Selain itu, logo halal menyatakan kriteria Islam yang diizinkan oleh hukum Islam, sedangkan bagi non-Muslim, produk bersertifikat halal dengan logo halal menegaskan keamanan, kebersihan dan kualitas makanan (Aziz \& Chok, 2013). Sehingga konsumen produk kosmetik halal tidak hanya Muslim namun nonmuslim pun tertarik untuk mengkonsumsi produk kosmetik halal.

Penelitian terdahulu yang dilakukan oleh Handriana, et al (2020); Khan, Sarwar, \& Tan (2020); Rahman, Asrarhaghighi, \& Rahman (2015); dan Ishak, Omar, Khalid, Ab. Ghafar , \& Hussain (2020) membahas terkait niat atau intensi membeli produk kosmetik halal. Sedangkan dalam penelitian ini akan meneliti terkait loyalitas konsumen khususnya perempuan milenial pada pembelian kosmetik halal. Urgensi dan alasan memilih loyalitas konsumen karena ingin mengetahui variabel yang mempengaruhi komitmen konsumen untuk membeli lagi suatu produk kosmetik halal di masa depan. Penelitian terdahulu, penentuan karakteristik responden yang dilakukan oleh Handriana, et al (2020); Khan, Sarwar, \& Tan (2020); Rahman, Asrarhaghighi, \& Rahman (2015); dan Ishak, Omar, Khalid, Ab. Ghafar ,\& Hussain (2020) terfokus pada perempuan muslim saja. Sedangkan responden dalam penelitian ini adalah perempuan milenial muslim dan non-muslim. Penelitian ini mencoba menjawab saran dengan melanjutkan penelitian sebelumnya (( Handriana, et al., 2020)(Khan, Sarwar, \& Tan, 2020)) untuk memasukkan perempuan milenial non-muslim sebagai responden. Selain itu, urgensi mengikutsertakan responden perempuan non-muslim karena meningkatnya daya tarik perempuan non-muslim terhadap kosmetik halal yang dianggap lebih sehat dan lebih aman (Mohezar, Zailani, \& Zainuddin, 2016)

Maka dari itu, pentingnya untuk dikaji terkait loyalitas pembelian produk kosmetik halal oleh perempuan milenial muslim dan non-muslim di Indonesia. Sehingga tujuan dari penelitian ini adalah untuk mengkaji keterkaitan religiusitas individu, sertifikasi halal, citra merek kosmetik halal, nilai keuntungan setelah menggunakan kosmetik halal, dan kepuasan konsumen terhadap loyalitas wanita terhadap pembelian kosmetik halal. 
METODE PENELITIAN

Penelitian ini menggunakan pendekatan survei kuantitatif dengan menyebar kuisioner yang berbentuk google form sehingga mudah diakses, namun tidak mengurangi keabsahan keuesioner. Kuisioner disebarkan menggunakan metode non-probability purposive sampling. Adapun teknik pengambilan sampel dengan purposive sampling dengan kriteria responden sebagai berikut:

1. Perempuan milenial yang lahir pada tahun 1980-an hingga 2000-an

2. Warga Negara Indonesia

3. Pernah melakukan pembelian kosmetik halal dalam 6 bulan terakhir.

Sebanyak 223 perempuan milenial menjadi responden dalam penelitian ini yang didominasi usia 20-25 tahun sebesar 91,5\%. Responden beragama Islam merupakan kontributor tertinggi dari total responden $(77,6 \%)$, Kristen $(12,6 \%)$, Hindu (6,3\%), Katolik $(3,1 \%)$, dan Buddha (0,4\%). Mayoritas responden $\quad(71,3 \%) \quad$ berpendidikan sarjana dan pekerjaan yang mendominasi adalah mahasiswa/pelajar sebesar $41,3 \%$ diikuti pegawai swasta sebesar 21,5\%. Dari total, 38,1\% responden berada dalam pendapatan kurang dari 1 juta rupiah. Dalam kurun waktu 6 bulan terakhir, mayoritas responden $(72,2 \%) \quad$ melakukan pembelian kosmetik halal sebanyak 2-3 kali.

Dalam penelitian ini menggunakan empat variabel eksogen, satu varibel intervening dan satu variabel endogen. Variabel eksogen meliputi religiusitas individu, citra merek, nilai keuntungan, dan sertifikasi halal. Variabel intervening yaitu kepuasan konsumen. Variabel endogen yakni loyalitas wanita terhadap pembelian kosmetik halal. Pengukuran indikator untuk variabel tersebut menggunakan skala likert lima poin, dengan kriteria sebagai berikut: 1 untuk sangat tidak setuju dan 5 untuk sangat setuju.

Gambar 1.

Model Konseptual Penelitian

Religiusitas Individu

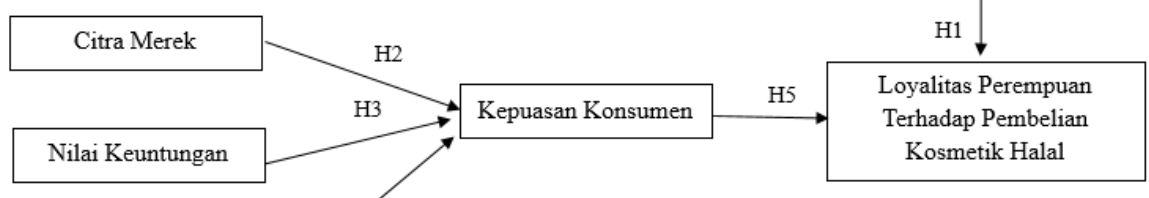

Sertifikasi Halal

PERFORMANCE : Jurnal Bisnis \& Akuntansi Volume 11, No.2 September 2021 


\section{FAKULTAS EKONOMI DAN BISNIS UNIVERSITAS WIRARAJA - MADURA}

Teknik analisis yang digunakan dalam penelitian ini adalah Structural Equation Modeling-Partial Least Square (SEM-PLS). Alasan penggunanaan SEM-PLS karena tujuan dari penelitian ini adalah untuk mengevaluasi hubungan antar konstruk variabel dan untuk menilai kekuatan prediksi dari variabel eksogen. Banyak peneliti juga yang mengkonfirmasi bahwa pendekatan SEM-PLS adalah alat statistik yang fleksibel, lebih kuat dan unggul untuk memprediksi dan menguji suatu teori (Henseler, Ringle, \& Sarstedt, 2015). Adapun software yang digunakan untuk melakukan analisis data dengan PLSSEM adalah SmartPLS 3.0.

\section{HASIL DAN PEMBAHASAN}

Hasil

Dalam penelitian ini, PLS-SEM digunakan untuk mengenali hubungan struktural antara variabel yang berbeda dan pengaruhnya dan untuk menguji hipotesis untuk penelitian ini. Terdapat dua tahap pengolahan SEM-PLS yaitu: tahap pengujian outer model dan tahap pengujian inner model.

Pengujian Outer Model

Pengujian outer model bertujuan untuk menjelaskan hubungan antar variabel laten dengan indikatornya. Menurut Ghozali (2014) pengujian outer model dapat dianalisis melalui tahapan-tahapan pengujian berikut:

1. Convergent Validity. Indikator dapat dikatakan valid apabila nilai loading factor $\geq 0,70$. Berdasarkan hasil output smartPLS pada Tabel 1 dan Gambar 1.., didapatkan hasil output indikator lebih dari 0,70 sehingga indikator dalam penelitian ini valid dan mewakili variabel laten dalam penelitian. 
Tabel 1.

Hasil Hitung Model

\begin{tabular}{|c|c|c|c|c|c|}
\hline Constructs & Items & $\begin{array}{l}\text { Loadings } \\
\text { Factor }\end{array}$ & $\begin{array}{l}\text { Cronbach's } \\
\text { alpha }\end{array}$ & $\begin{array}{c}\text { Composite } \\
\text { Reability }\end{array}$ & AVE \\
\hline \multirow[t]{2}{*}{ Religiusitas } & R4 & 0.937 & 0.804 & 0.909 & 0.834 \\
\hline & R5 & 0.889 & & & \\
\hline \multirow[t]{3}{*}{ Citra Merek } & CM1 & 0.773 & 0.786 & 0.876 & 0.702 \\
\hline & CM3 & 0.875 & & & \\
\hline & CM4 & 0.862 & & & \\
\hline Nilai & NK1 & 0.843 & 0.876 & 0.915 & 0.731 \\
\hline \multirow[t]{3}{*}{ Keuntungan } & NK2 & 0.894 & & & \\
\hline & NK3 & 0.877 & & & \\
\hline & NK4 & 0.802 & & & \\
\hline Sertifikasi & SH1 & 0.881 & 0.907 & 0.935 & 0.782 \\
\hline \multirow{3}{*}{ Halal } & $\mathrm{SH} 2$ & 0.886 & & & \\
\hline & SH3 & 0.868 & & & \\
\hline & SH4 & 0.903 & & & \\
\hline Keриаsаn & KK1 & 0.860 & 0.867 & 0.904 & 0.654 \\
\hline \multirow[t]{4}{*}{ Konsumen } & KK2 & 0.783 & & & \\
\hline & KK3 & 0.741 & & & \\
\hline & KK4 & 0.866 & & & \\
\hline & KK5 & 0.785 & & & \\
\hline \multirow[t]{5}{*}{ Loyalitas } & L1 & 0.813 & 0.878 & 0.912 & 0.912 \\
\hline & L2 & 0.865 & & & \\
\hline & L3 & 0.813 & & & \\
\hline & L4 & 0.881 & & & \\
\hline & L5 & 0.726 & & & \\
\hline
\end{tabular}

Gambar 1.

Diagram Jalur disertai Nilai Loading Factor

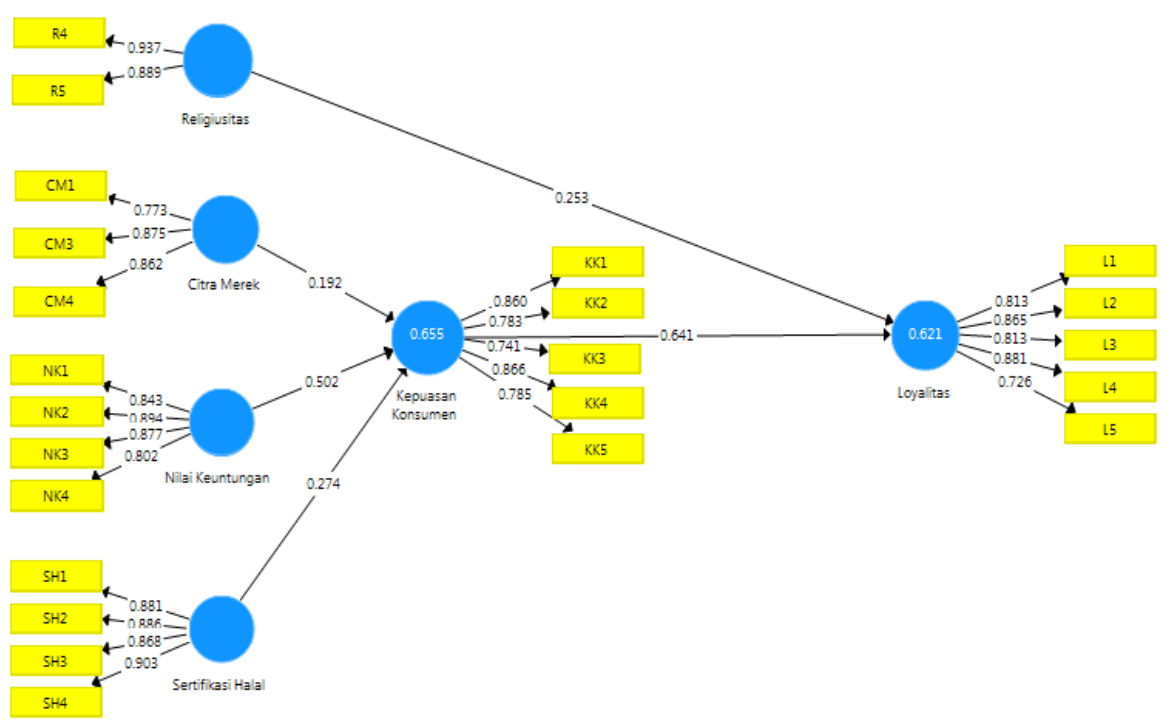


2. Discriminant Validity, untuk mengukur seberapa jauh konstruk benar-benar berbeda dengan konstruk lainnya dengan menggunakan analisis FornellLacker Criterion yaitu uji validitas yang dilakukan dengan membandingkan korelasi antar variabel atau konstruk dengan akar kuadrat dari Average Variance Extracted $\quad(\sqrt{ } A V E) . \quad$ Prediksi dikatakan memiliki nilai AVE yang baik apabila nilai $\sqrt{ } A V E$ setiap variabel laten lebih besar dari korelasi antar variabel laten lainnya. Berikut adalah tabel Fornell-Lacker Criterion:

3. Discriminant Validity, untuk mengukur seberapa jauh konstruk benar-benar berbeda dengan konstruk lainnya dengan menggunakan analisis FornellLacker Criterion yaitu uji validitas yang dilakukan dengan membandingkan korelasi antar variabel atau konstruk dengan akar kuadrat dari Average Variance Extracted $\quad(\sqrt{ } A V E) . \quad$ Prediksi dikatakan memiliki nilai AVE yang baik apabila nilai $\sqrt{ } A V E$ setiap variabel laten lebih besar dari korelasi antar variabel laten lainnya. Berikut adalah tabel Fornell-Lacker Criterion:
Berdasarkan Tabel 2., terlihat bahwa nilai $\sqrt{ } A V E$ setiap variabel laten lebih besar dari korelasi antar variabel laten lainnya. Hal ini menunjukkan bahwa konstruk memiliki diskriminan yang baik.

1. Average Variance Extracted (AVE). Berdasarkan Tabel 1. seluruh variabel pada penelitian memiliki nilai AVE lebih dari 0,50, membuktikan bahwa seluruh variabel laten pada penelitian ini dikatakan baik dalam mewakili indikator.

2. Composite Reliability, untuk mengukur reliabilitas model pengukuran atau internal konsistensi. Nilai composite reliability yang tinggi menunjukkan nilai konsistensi dari masing-masing indikator dalam mengukur konstruknya dengan melihat nilai composite reliability dan cronbach's alpha yang nilainya harus lebih besar dari 0,70. Berdasarkan Tabel 1 enunjukkan bahwa seluruh variabel laten pada penelitian ini mempunyai nilai cronbach's alpha dan composite reliability lebih dari 0,70 . Oleh karena itu, dapat disimpulkan bahwa seluruh variabel laten pada penelitian ini dikatakan reliabel dan model yang dibangun memiliki tingkat reliabilitas yang sangat baik. 
Tabel 2.

Fornell-Lacker Criterion

\begin{tabular}{lcccccc}
\hline Citra & $\begin{array}{c}\text { Kepuasan } \\
\text { Merek } \\
\text { Konsumen }\end{array}$ & Loyalitas & $\begin{array}{c}\text { Nilai } \\
\text { Keuntungan }\end{array}$ & Religiusitas & $\begin{array}{c}\text { Sertifikasi } \\
\text { Halal }\end{array}$ \\
$\begin{array}{l}\text { Citra Merek } \\
\text { Kepuasan }\end{array}$ & 0.838 & & & & & \\
Konsumen & 0.650 & 0.809 & & & & \\
Loyalitas & 0.591 & 0.755 & 0.821 & & & \\
$\begin{array}{l}\text { Nilai } \\
\text { Keuntungan }\end{array}$ & 0.604 & 0.733 & 0.605 & 0.855 & & \\
Religiusitas & 0.494 & 0.449 & 0.541 & 0.290 & 0.913 & \\
Sertifikasi & 0.564 & 0.592 & 0.700 & 0.418 & 0.696 & 0.884 \\
Halal & & & & & & \\
\hline
\end{tabular}

Berdasarkan hasil pengujian pada outer model yaitu dengan menguji convergent validity, discriminant validity, average variance extracted (AVE), dan composite reliability dapat disimpulkan bahwa outer model dalam penelitian ini telah memenuhi syarat yang ditentukan dalam tahap-tahap penelitian PLS. Oleh karena itu penelitian ini layak untuk dilanjutkan ke tahap selanjutnya.

\section{Pengujian Inner Model}

Pengujian inner model bertujuan untuk mengetahui pengaruh antar model menggunakan uji $\mathrm{t}$ dan mengetahui penerimaan atau penolakan hipotesis dapat dilihat dari bootstraping report. Berdasarkan Tabel 3.,maka analisis penerimaan atau penolakan hipotesis dapat dilakukan, Adapun penjelasannya sebagai berikut:

1. Pengujian Hipotesis 1 Pengaruh Religiusitas (X1) terhadap Loyalitas (Y). Hasil menunjukkan nilai $t$-statistic $4,936>1,96$ dan nilai p-value sebesar $0.000<0,05$ artinya variabel religiusitas memiliki pengaruh yang positif dan signifikan terhadap loyalitas konsumen.

2. Pengujian Hipotesis 2 Citra Merek (X2) terhadap Kepuasan Konsumen. Hasil menunjukkan nilai $t$-statistic $3,507>1,96$ dan nilai p-value sebesar $0.000<0,05$ artinya variabel citra merek memiliki pengaruh positif dan signifikan terhadap kepuasan konsumen.

3. Pengujian Hipotesis 3 Nilai Keuntungan (X3) terhadap Kepuasan Konsumen. Hasil menunjukkan nilai $t$-statistic 9.107 $>1,96$ dan nilai $\mathrm{p}$-value sebesar $0.000<0,05$ artinya variabel nilai keuntungan memiliki pengaruh positif dan signifikan terhadap kepuasan konsumen 
Tabel 3 .

Estimasi Nilai Koefisien Variabel

\begin{tabular}{rcccc}
\hline Hypothesis relationship & $\begin{array}{c}\text { Original } \\
\text { Sample } \\
(\mathbf{O})\end{array}$ & $\begin{array}{c}\text { T Statistics } \\
(|\mathbf{O} / \mathbf{S T D E V}|)\end{array}$ & P Values & $\begin{array}{c}\text { Hypothesis } \\
\mathbf{a c c e p t}\end{array}$ \\
\hline Religiusitas -> Loyalitas & 0.253 & 4.936 & 0.000 & H1 diterima \\
\hline $\begin{array}{r}\text { Citra Merek -> Kepuasan } \\
\text { Konsumen }\end{array}$ & 0.192 & 3.507 & 0.000 & H1 diterima \\
$\begin{array}{r}\text { Nilai Keuntungan -> } \\
\text { Kepuasan Konsumen }\end{array}$ & 0.502 & 9.107 & 0.000 & H1 diterima \\
$\begin{array}{r}\text { Sertifikasi Halal -> } \\
\text { Kepuasan Konsumen }\end{array}$ & 0.274 & 4.272 & 0.000 & H1 diterima \\
$\begin{array}{r}\text { Kepuasan Konsumen -> } \\
\text { Loyalitas }\end{array}$ & 0.641 & 14.055 & 0.000 & H1 diterima \\
\hline
\end{tabular}

4. Pengujian Hipotesis 4 Sertifikasi Halal (X4) terhadap Kepuasan Konsumen. Hasil menunjukkan nilai $t$-statistic $4.272>1,96$ dan nilai $p$-value sebesar $0.000<0,05$ artinya variabel sertifikasi halal memiliki memiliki pengaruh positif dan signifikan terhadap kepuasan konsumen.

5. Pengujian Hipotesis 5 Kepuasan Konsumen terhadap Loyalitas Hasil menunjukkan nilai $t$-statistic $14.055>1,96$ dan nilai $p$-value sebesar $0.000<0,05$ artinya variabel kepuasan konsumen memiliki pengaruh positif dan signifikan terhadap loyalitas konsumen.

\section{PEMBAHASAN}

Tujuan dari penelitian ini adalah untuk menguji variabel religiusitas individu, citra merek kosmetik halal, sertifikasi halal, nilai keuntungan, dan kepuasan konsumen terhadap loyalitas wanita terhadap pembelian kosmetik halal.

$$
\text { Berdasarkan hasil pengujian }
$$

SEM, menujukkan bahwa diterimanya H1 dimana religiusitas merupakan determinan yang signifikan dan berpengaruh terhadap loyalitas perempuan dalam pembelian kosmetik halal. Temuan ini membantah temuan sebelumnya (Suhartanto, et al., 2020) dan membuktikan bahwa religiusitas memainkan peranan penting dalam loyalitas konsumen dalam pembelian kosmetik halal. Responden penelitian tidak hanya perempuan beragama Islam namun juga agama Kristen, Katolik, Buddha dan Hindu, sehingga menunjukkan bahwa produk halal khususnya kosmetik halal tidak hanya untuk pemeluk agama Islam namun semua agama dapat mengonsumsinya dan menjadikan sebagai pilihan gaya hidup. 
Adapun citra merek menjadi determinan yang signifikan dan berpengaruh positif terhadap kepuasan konsumen (H2 diterima). Artinya, kepuasan konsumen terhadap produk kosmetik halal ditentukan oleh citra merek dari produk kosmetik halal tersebut. Citra merek yang baik di mata konsumen membuat mereka memiliki sikap yang baik terhadap produk produk kosmetik halal. Bagi perempuan milenial, citra merek kosmetik halal yang baik menjadi penting karena citra merek yang positif akan menjadi sebuah alasan untuk mereka menunjukkan produk kosmetik halal kepada teman yang umumnya dilakukan di media sosial. Temuan penelitian ini sejalan dengan penelitian yang dilakukan oleh Handriana (2020) dimana citra merek mempengaruhi sikap konsumen. Dalam hal ini sikap menjadi hal yang penting terhadap suatu merek yang diartikan sebagai sikap negatif dan positif misalnya kepuasan konsumen atas produk kosmetik halal.

Sejalan dengan $\mathrm{H} 2$, pernyataan pada H3 diterima dimana nilai keuntungan memiliki pengaruh positif terhadap kepuasan konsumen. Nilai keuntungan dalam hal ini berkaitan dengan manfaat yang diperoleh oleh konsumen saat mengonsumsi produk kosmetik halal. Tingginya nilai keuntungan yang diperoleh konsumen akan membuat konsumen semakin merasa puas pada produk kosmetik halal. Temuan ini mendukung penelitian sebelumnya(Zeithaml, Berry, \& Parasuraman, 1996)bahwa menyatakan bahwa nilai positif yang dirasakan atas suatu produk akan mempengaruhi tingkat kepuasan konsumen dan merangsang mereka untuk membeli kembali serta merekomendasikan merek tertentu kepada orang lain.

Diterimanya $\mathrm{H} 4$ artinya sertifikasi halal berpengaruh positif terhadap kepuasan konsumen. Hal ini menunjukkan bahwa perempuan milenial mempertimbangkan sertifikasi halal untuk memenuhi kepuasan dalam mengonsumsi kosmetik halal. Hal tersebut sejalan dengan penelitian sebelumnya (Aziz, Husin, Hussin, \& Afaq, 2019) menyatakan bahwa produk bersertifikat halal dengan logo halal bagi umat Islam membawa ketenangan pikiran karena menjadi penanda utama pembeda produk halal dan non halal. Sedangkan untuk pemeluk agama lainnya, produk bersertifikat halal dengan logo halal menegaskan keamanan, kebersihan dan kualitas makanan.

Terakhir, dari hasil uji H5, menunjukkan bahwa kepuasan konsumen berpengaruh positif terhadap loyalitas perempuan milenial dalam pembelian kosmetik halal. Dalam hal ini 
kepuasan konsumen merupakan variabel intervening atas citra merek, nilai keuntungan dan sertifikasi halal terhadap loyalitas konsumen. Ini mendukung anggapan bahwa konsumen mengaitkan kehalalan dengan atribut produk, citra merek, nilai manfaat yang diperoleh dan sertifikasi halal produk sebagai pedorong kepuasan konsumen. Semakin tinggi kepuasan konsumen pada produk kosmetik halal akan semakin meningkatkan pula loyalitas yang diberikan. Temuan ini mendukung penelitian yang dilakukan sebelumnya (Suhartanto, et al., 2020) bahwa konsumen yang memperoleh nilai keuntungan atas produk kosmetik halal akan merasa puas dan akan bersifat loyal dengan melakukan pembelian kembali serta merekomendasikan produk tersebut kepada orang lain.

\section{KESIMPULAN DAN IMPLIKASI}

\begin{tabular}{|c|c|}
\hline Berdasarkan & hasil \\
\hline menunjukkan & bahwa \\
\hline
\end{tabular}
loyalitas perempuan milenial dalam pembelian kosmetik halal (H1). Hal ini diluar dugaan karena responden dalam penelitian ini tidak hanya perempuan muslim namun juga agama lainnya yakni Kristen, Katolik, Hindu dan Buddha. Hasil empiris menunjukkan bahwa citra merek (H2), nilai keuntungan (H3) dan sertifikasi halal (H4) berpengaruh signifikan dan positif terhadap kepuasan konsumen. Tingginya tingkat kepuasan ternyata memiliki pengaruh yang positif pula terhadap loyalitas perempuan milenial dalam melakukan pembelian kembali produk kosmetik halal dan merekomendasikannya kepada orang lain.

Penemuan ini memiliki implikasi yang signifikan yang dapat membantu produsen dan distributor dalam mengembangkan strategi bisnis yang sesuai untuk produk kosmetik halal. Hubungan positif antara religiusitas dan loyalitas konsumen, merupakan angin segar bagi produsen untuk berani mengembangkan sayapnya memperkenalkan produk kosmetik halal tidak hanya untuk konsumen muslim namun juga non muslim. Dalam hal ini, adanya ketertarikan tidak hanya dari konsumen muslim namun juga non muslim untuk menggunakan produk kosmetik halal sehingga rekomendasi untuk perusahaan atau produsen kosmetik halal memposisikan produknya berdasarkan pentingnya citra merek, nilai keuntungan, dan sertifikasi halal sebagai atirbut unik produk yang mampu mempengaruhi konsumen dalam pengambilan keputusan pembelian produk kosmetik halal yang dimaksud. 
Batasan dan Rekomendasi Penelitian

\section{Masa Depan}

Meskipun studi ini telah memperluas studi tentang loyalitas terhadap kosmetik halal dengan responden perempuan muslim dan nonmuslim namun memiliki keterbatasan yang perlu dipertimbangkan. Penelitian ini hanya berfokus pada variabel kepuasan konsumen sebagai variabel intervening antara citra merek, nilai keuntungan dan sertifikasi halal terhadap loyalitas konsumen. Oleh karena itu, diperlukan penelitian lebih lanjut untuk melakukan penelitian dengan pendekatan kualitatitf untuk mendapatkan hasil studi yang lebih mendalam terkait loyalitas pembelian kosmetik halal. Selain itu, peneliti disarankan untuk melakukan uji komparasi dengan menggunakan sampel penelitian konsumen kosmetik halal dari negara yang lainnya.

\section{DAFTAR PUSTAKA}

Aisyah, M. (2017). Consumers demand on halal cosmetics and personal care products in Indonesia. AlIqtishad, Vol. 9 No. 1, pp. 125 142.

Ambali , A., \& Bakar, A. (2014). People's awareness on halal foods and products: potential issues for policy-makers. Procedia - Social and Behavioral Sciences, Vol. 121, pp. 3-25, doi 10.1016/j.sbspro.2014.01.1104.

Atnasari, R., Gunawan, S., Possumah, B., Rusmita, S., \& Widiastuti, T. (2019). Halal food certification for improving the competitiveness of small and medium enterprises. Vol. 35 No. 22 , pp. $510-525$.

Aziz, S., Husin, M., Hussin, N., \& Afaq, Z. (2019). Factors that influence individuals' intentions to purchase family takaful mediating role of perceived trust. Asia Pacific Journal of Marketing and Logistics, Vol. 31 No. 1, doi: 10.1108/APJML12-2017-0311.

Aziz, Y., \& Chok, N. (2013). The role of awareness, certification, and marketing components in determining purchase intention among non-Muslims in Malaysia: a structural equation modelling approach. Journal of International Food and Agribusiness Marketing, Vol. 25 No. 1,pp. 1-23

Budiarti, I. S. (2018). Statistik gender tematik: Profil generasi milenial indoneia. Jakarta: Kementerian pemberdayaan perempuan dan perlindungan anak.

Chen, Y., \& Chang, C. (2012). Enhance green purchase intentions the roles of green perceived value, green perceived risk, and green trust. Management Decision, Vol. 50 No. 3, pp. 502-520, doi: 10.1108/00251741211216250.

Chinomona, R. (2016). Brand communication, brand image and brand trust as antecedents of brand loyalty in Gauteng province of South Africa", African. Journal of Economic and Management Studies, Vol. 7 No. 1, pp. 124-139.

De Run, E., Butt, M., Fam, K.-S., \& Jong, H. (2010). Attitudes towards offensive advertising: Malaysian Muslims' views. Journal of Islamic Marketing, Vol. 1 No. 1, pp. 25-36. 
Fischer, J. (2019). Looking for religious logos in Singapore. Journal of Management, Spirituality and Religion, Vol. 16 No. 1, pp. 132-153.

Fromm, J., \& Garton, C. (2013). Marketing to Millennials: Reach the Largest and Most Influential Generation of Consumers Ever. New York: AMACOM.

Gerzema, J., \& D’Antonio, M. (2011). Spend Shift: How the Post-crisis Values Revolution Is Changing the Way We Buy, Sell, and Live, Jossey-Bass. San Francisco: CA.

Ghozali, I. (2014). Structural Equation Modeling Metode Alternatif dengan Partial Least Squares (PLS). Dilengkapi Software Smartpls 3.0. Xlstat 2014 dan WarpPLS 4.0 (4th ed). Semarang: Badan Penerbit Universitas Diponegoro.

Handriana, T., Yulianti, P., Kurnia, M., Arina, N. A., Aisyah, R. A., Aryani, M. G., \& Wandira, R. K. (2020). Purchase Behavior of Millennial Female Generation on Halal Cosmetic Products. Journal of Islamic Marketing.

Hanzaee, K., \& Ramezani, M. (2011). Intention to halal products in the world markets. Interdisciplinary Journal of Research in Business, Vol. 1 No. 5, pp. 1-7.

Henseler, J., Ringle, C., \& Sarstedt, M. (2015). A new criterion for assessing discriminant validity in variance-based structural equation modeling. Journal of the Academy of Marketing Science, 43(1), 115-135. https://doi.org/10.1007/s11747014-0403-8.

Hussain-Gambles, M. (2020). Halal personal hygiene and cosmetics. in Al-Teinaz, Y.R., Spear, S. and Abd El-Rahim, I.H.A. (Eds), The
Halal Food Handbook, wiley, Hoboken, NJ.

Ishak, S., Omar, A. R., Khalid, K., Ab. Ghafar, I. S., \& Hussain, M. Y. (2020). Cosmetics purchase behavior of educated millennial Muslim females. Journal of Islamic Marketing, Vol. 11 No. 5 pp. 1055-1071.

Johnson, B., Jang, S., Larson, D., \& De Li, S. (2001). Does adolescent religious commitment matter?Areexamination of the effects of religiosity on delinquency. Journal of Research in Crime and Delinquency, Vol. 38 No. 1, pp. 22-44.

Khan, N., Sarwar, A., \& Tan, B. C. (2020). Determinants of Purchase Intention of Halal Cosmetic Products among Generation Y Consumers. Journal of Islamic Marketing.

Kotler, P., \& Keller, K. (2016). Marketing Management, 15th ed. London: Pearson Education.

Levy, S. a. (2016). Emotional Brand attachment: a factor in customer-bank relationships. International Journal of Bank Marketing, Vol. 34 No. 2, pp. 136-150, doi: 10.1108/JJBM-062015-0092.

Liao, C. L.-N. (2017). Factors influencing online shoppers' repurchase intentions: the roles of satisfaction and regret. Information and Management, Vol. 54 No. 5,pp. 651-668.

Low, G., \& Lamb, C. (2000). The measurement and dimensionality of brand association. Journal of Product \& Brand Management, Vol. 9 No. 6, pp. 350-368.

Marketing Breakthroughs Inc. (2008, November 1). Five tips on successfully advertising to Gen- 
$Y$. Retrieved from Marketing Breakthroughs Inc., November: www.marketingbreakthroughs.c om

McCormick, K. (2016). Celebrity endorsements: influence of a product- endorser match on millennials attitudes and purchase intentions. Journal of Retailing and Consumer Services, Vol. 32,pp. 39-45.

Mohezar, S., Zailani, S., \& Zainuddin, Z. (2016). Halal cosmetics adoption among young Muslim consumers in Malaysia: religiosity concern. Global Journal Al Thaqafah, Vol. 6 No. 1, pp. 47-59.

Moira, P., Sarchosis, D., \& Mylonopoulos, D. (2017). The religious beliefs as parameter of food choices at tourist destination: the case of Mykonos", International Religious Tourism and Pilgrimage Conference. Retrieved from http://arrow.dit.ie/irtp/2017/conc erns/4/

Mudambi, S., Doyle, P., \& Wong, V. (1997). An exploration of branding in industrial markets. Industrial Marketing Management, Vol. 26 No. 5, pp. 433-446.

Oliver, R. (1999). Whence consumer loyalty? Journal of Marketing, Vol. 63 No. 4_suppl1, pp. 3344, doi: $10.2307 / 1252099$.

Rahman, A. A., Asrarhaghighi, E., \& Rahman, S. A. (2015). Consumers and Halal cosmetic products: knowledge, religiosity, attitude and intention. Journal of Islamic Marketing, Vol. 6 No. 1,pp. 148-163.

Selim, N. Z. (2019). Halal logistic services, trust and satisfaction amongst Malaysian 3PL service providers. Journal of Islamic Marketing.

Shafie, S., \& Othman, M. (2006). Halal certification: an international marketing issues and challenges. Proceedings of the 2006 IFSAM VIIIth World Congress, (pp. pp. 28-30).

Smith, K. T. (2012). Longitudinal study of digital marketing strategies targeting millennials. Journal of Consumer Marketing, Vol. 29 No. 2, pp. 86-92, doi: 10.1108/07363761211206339.

Suhartanto, D., Dean, D., Sarah, I. S., Hapsari, R., Amalia, F. A., \& Suhaeni, T. (2020). Does religiosity matter for customer loyalty? Evidence from halal cosmetics. Journal of Islamic Marketing, DOI 10.1108/JIMA03-2020-0069.

Xiao, Y. R. (2019). The effect of service quality on foreign participants' satisfaction and behavioral intention with the 2016 shanghai international marathon. International Journal of Sports Marketing and Sponsorship, Vol. 21 No. 1, pp. 91-105.

Zeithaml, A., Berry, L., \& Parasuraman, A. (1996). The behavioral consequences of service quality. Journal of Marketing, Vol. 60 No. 2, pp. 31-46. 